\title{
Salmonella Contamination of Fresh Salad Produce: Prevalence, Impact and Reduction Strategies
}

\author{
Koukkidis $\mathrm{G}$ and Freestone $\mathrm{P}^{*}$ \\ Department of Infection, Immunity and Inflammation, Maurice Shock Medical Sciences Building, University of \\ Leicester, UK
}

${ }^{*}$ Corresponding author: Freestone P, Department of Infection, Immunity and Inflammation, Maurice Shock Medical Sciences Building, University of Leicester, University Road, Leicester LE1 7RH UK, Tel: +44 (0)116 252 5656, E-mail: ppef1@le.ac.uk

Citation: Koukkidis G, Freestone P (2019) Salmonella Contamination of Fresh Salad Produce: Prevalence, Impact and Reduction Strategies. J Horti Sci Crop Res 1(1): 102

Received Date: March 2, 2018 Accepted Date: May 8, 2019 Published Date: May 10, 2019

\begin{abstract}
Fresh salad produce such as lettuce and spinach are an important part of a healthy diet, but are increasingly becoming associated with infection from foodborne pathogens such as Salmonella enterica. This review examines the incidence and origins of Salmonella fresh salad leaf colonization, models the behaviour of the pathogen when within a bagged salad and considers the various infection risk reduction strategies relevant to salad growers, distributors and consumers which can be employed to improve the microbiological safety of fresh salad leaves
\end{abstract}

Keywords: Salmonella; Salad Leaves; Infection

\section{Introduction}

Fresh salad vegetables such as lettuce, spinach and herbs, and bean sprouts are an important part of a healthy diet, providing vitamins, minerals, and dietary fiber. Ready to eat bagged salads are most popular with consumers, and represent an important economic output $[1,2]$. Over the last 10 years or so salad produce consumption has also become associated with food poisoning outbreaks through contamination with enteric pathogens such as Salmonella enterica, Listeria monocytogenes, and Escherichia coli. Although such outbreaks have led to development of strategies for improved prevention of pathogen contamination, their success is limited and salad leaves are now recognized as one of the most common source of foodborne illness [3-5]. In the USA and Europe fresh salad produce outbreaks have been reported for all of these pathogens, but usually the greatest health impact in terms of treatment requiring hospitalisation has been associated with Salmonella infections [3-5]. This review considers the prevalence of Salmonella contamination of fresh salad produce, explores what happens when the pathogen encounters salad leaves, and discusses recent strategies aimed at reducing salad leaf-associated infections.

\section{Prevalence: Outbreaks and Impact}

Salad leaves have high water content and after harvesting quickly become subject to spoilage by a range of bacteria and fungi, which therefore requires leaves to be rapidly processed into specialist sealed containers with a low oxygen atmosphere. As a fresh produce, leafy salads are consumed raw, which makes them subject to an infection risk if contaminated with food poisoning microorganisms [3]. Salad leaves have been shown to be susceptible to colonization by enteric pathogens, one of the most problematic of which is Salmonella [3,6-10]. Outbreak studies over the last decade reveal there is a considerable human health burden associated with salad produce infections by this pathogen (Table 1). In the US in 2014 contaminated Salmonella bean sprouts infected over 100 people, a quarter of whom were hospitalized [11]. Salmonella enterica serovar Thompson contamination of bagged ready-to-eat rocket salad leaves originating from Italy caused a serious outbreak in the UK and Scandinavia in 2004 with 30 confirmed cases, but estimates of considerably higher numbers of people were affected [12]. In Denmark in 2009 fresh basil contaminated by Salmonella enterica serovar Anatum infected over 200 school students and teachers, though without fatalities [13]. In February 2016, more than 50 people in Victoria, Australia, developed salmonellosis after eating salad leaves [14]. Such outbreaks are usually associated with huge economic consequences to consumers and employers due to the lost days spent for recovering from the food poisoning but also to the producers who usually experience massive drop of their sales after such incidents. But most importantly the producers' 
sector are hit massively, as in the case of the outbreak in Australia last year where a Tasmanian producer reported a $40 \%$ drop in sales nationwide causing him a loss of $\$ 500,000$ even though the company had absolutely no link with the specific outbreak [15]. Due to the growing numbers of salad related outbreaks, the European Food Safety Authority (EFSA) Panel on Biological Hazards has now categorised leafy green salads as the second most frequent source of foodborne infection within the European Union, with Salmonella being implicated in around 30\% of fresh produce outbreak cases [16]. Salmonella infections from fresh produce can be severe, particularly in children, the elderly or immunocompromised $[3,17,18]$. The infectious dose of Salmonella is generally thought to be around 10,000 cells although depending on the food origin and outbreak strain characteristic some reports have shown the infectious dose can be as low as 10-100 bacteria $[3,17,18]$. In the United States Salmonella is estimated to cause 1 million foodborne infections every year with 19,000 hospitalizations and nearly 400 avoidable deaths causing considerable damage to society and the economy of the country [19]. According to the EFSA 2016 report there were almost 100000 confirmed Salmonellosis cases in Europe and 126 reported deaths [20]. The increased consumption of fresh produce and ready to eat fresh salad produce over the last decade in the USA and Europe has contributed unavoidably to an increase of foodborne outbreaks associated with fresh produce [21].

\begin{tabular}{|c|c|c|c|c|c|}
\hline Salmonella strain & Fresh Produce type & Number of cases & Year & Country & Reference \\
\hline Salmonella Montevideo & Raw Sprouts & 8 & 2018 & USA & 46 \\
\hline $\begin{array}{c}\text { Salmonella Muenchen } \\
\text { and Salmonella Kentucky }\end{array}$ & Alfalfa Sprouts & 26 & 2016 & USA & 47 \\
\hline $\begin{array}{c}\text { Salmonella } \text { Reading and } \\
\text { Salmonella Abony }\end{array}$ & Alfalfa Sprouts & 36 & 2016 & USA & 48 \\
\hline Salmonella Anatum & Lettuce & 54 & 2016 & Australia & 49 \\
\hline Salmonella Poona & Cucumber & 907 & 2015 & USA & 50 \\
\hline Salmonella Enteritidis & Bean Sprouts & 115 & 2014 & USA & 51 \\
\hline Salmonella Newport & Cucumber & 275 & 2014 & USA & 52 \\
\hline Salmonella Enteritidis & $\begin{array}{c}\text { Alfalfa Sprouts and } \\
\text { Spicy Sprouts }\end{array}$ & 25 & 2011 & USA & 53 \\
\hline Salmonella Enteriditis & Alfalfa Sprouts & 140 & $2010-2011$ & USA & 54 \\
\hline Salmonella Newport & Alfalfa Sprouts & 44 & 2010 & USA & 55 \\
\hline Salmonella Saintpaul & Alfalfa Sprouts & 235 & 2009 & USA & 56 \\
\hline $\begin{array}{c}\text { Salmonella } \text { enterica } \\
\text { Bovismorbificans }\end{array}$ & Alfalfa seeds & 42 & 2009 & Finland & 57 \\
\hline Salmonella Stanley & Alfalfa sprouts & 51 & 2007 & Sweden & 58 \\
\hline Salmonella Weltevreden & Alfalfa Sprouts & 45 & 2007 & $\begin{array}{c}\text { Norway, } \\
\text { Denmark, Finland }\end{array}$ & 59 \\
\hline
\end{tabular}

Table 1: Global foodborne outbreaks connected with leafy greens, salads and sprouts Salmonella contamination between 2007 and 2018.

\section{Routes of Salad Leaf Contamination}

Salad leaves (predominantly lettuces, spinach and leafy herbs) are largely water and carbohydrate in terms of composition and as a consequence cellular decay contributed to by spoilage microbes initiates soon after harvesting, which means salad leaves must be processed rapidly after picking. Salad leaves naturally acquire a diverse endogenous microflora during cultivation but this does not competitively exclude subsequent colonization by enteric pathogens, particularly Salmonella and E. coli O157:H7 [3,6-10]. Why pathogens normally associated with meat products can also infect salad leaves is not entirely clear, though the potential pathways to fresh produce contamination are well known [3]. It has been suggested that animal and insect contact during salad leaf growth, faecal contamination of soil or compost, pathogen presence within irrigation and wash waters, and contaminated equipment combined with poor hygiene of human salad packers are all contributory factors $[3,16]$. Trials have shown that when enteric pathogens such as Salmonella and E. coli are established in soils or compost they can internalise seeds, which could then increase pathogen dissemination over considerable geographical distances [3]. Additionally, a pathogen presence with seeds would aid later colonisation of plant tissues during germination by invading the root hairs and travelling to distant sites via the plant phloem and xylem $[18,22]$. Salmonella displays a positive chemotactic response to fluids released from fresh produce roots and when inoculated into plant culture media rapidly colonized the interior tissues of tomatoes [23,24]. While these analyses are laboratory based and used high levels of bacterial inoculum which may not be reached in fresh produce cultivation soils, such findings are important as they reveal that internalization of plant tissues is a possible source of non-eradicable enteropathogen fresh produce contamination. Harvesting salad leaves involves cutting off of the leaf stalks, removal of damaged leaves also by cutting, washing the salad head in clean cold water, packaging, and finally transport to the supermarket, which means it can be several days before harvested plants are consumed [3]. Physical damage to salad leaves from salad cutting has been shown to promote the growth of Salmonella, especially at non-refrigeration temperatures $[3,6,8]$. Once internalized within a salad plant, Salmonella has been shown to grow well within salad leaf tissues as well as on the surface of leaves, particularly at cut surfaces where leaf fluids are release 
$[25,26]$. Practices designed to inhibit pathogen growth in fresh salad produce include refrigeration after harvesting and packaging in a modified atmosphere containing reduced oxygen levels $[3,16]$. Despite the efforts at reducing the risk of salad-associated infections they continue to occur, largely because most points of the path of salad leaf production has multiple opportunities for microbial pathogen colonization.

\section{Molecular Studies of Salmonella Salad Leaf Interactions}

Although most research effort has been directed at improving the hygiene of salad cultivation, much less is known about what happens to pathogens such as Salmonella when they have entered the salad bag. We carried out such an investigation and examined aspects of Salmonella biology relevant to leaf colonization and host infectivity [27]. This study found that microliter traces of juices present within salad leaves, including juices leached into salad bag water films, massively increased Salmonella growth by over 3 logs, even at refrigeration temperatures, which is of particular relevance to salad leaf storage by consumers (Figure 1).

A

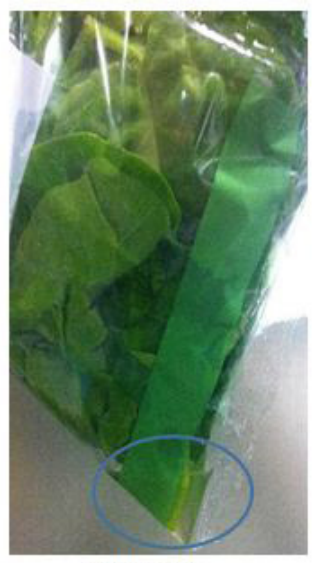

Spinach

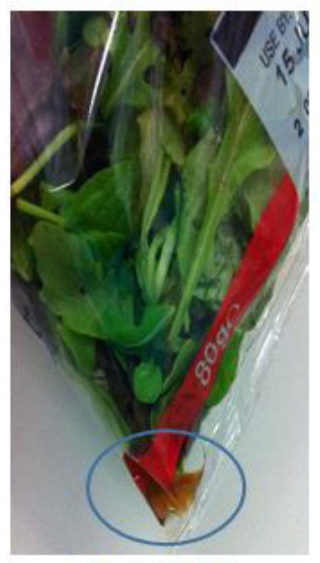

Mixed leaf

B

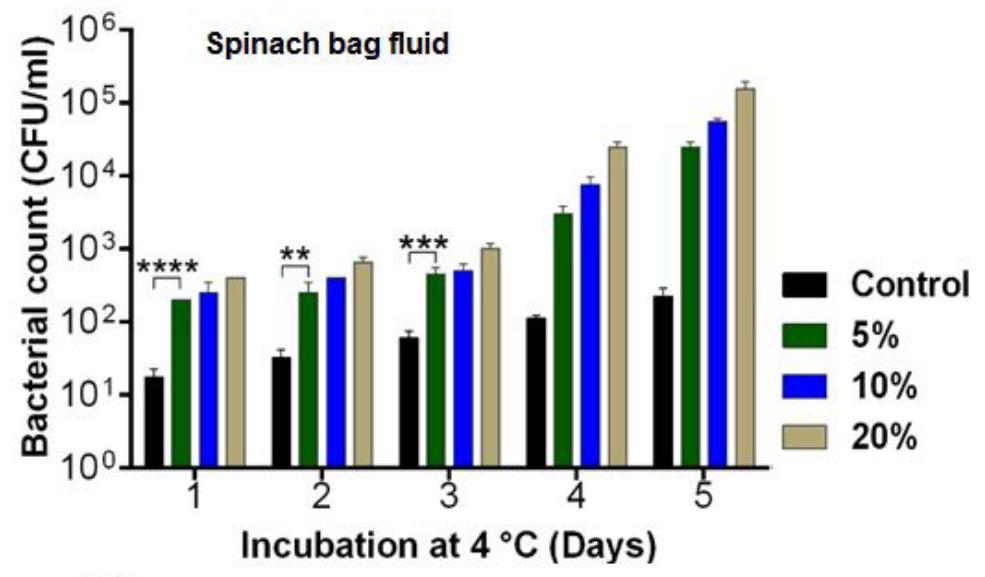

C

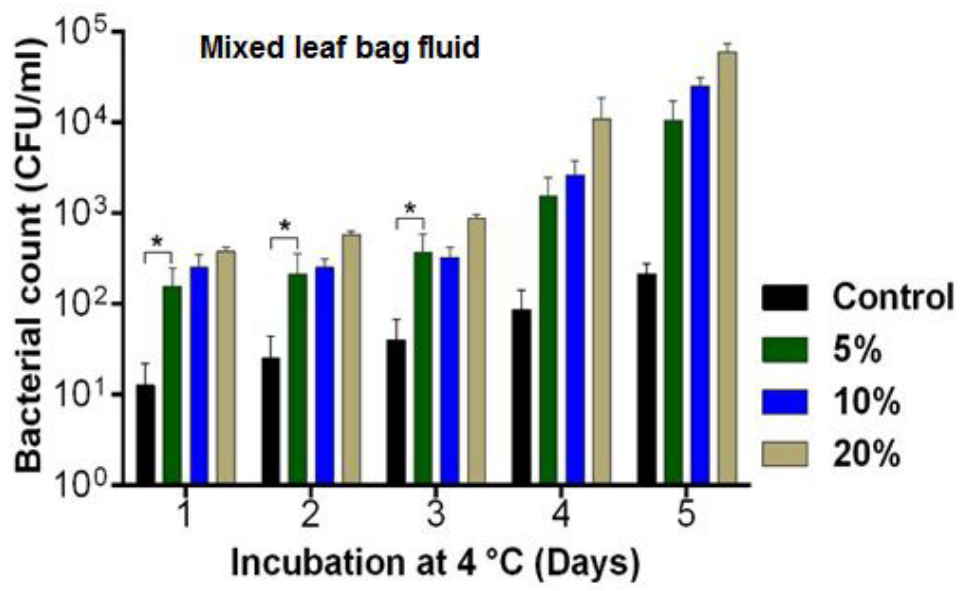

Figure 1: Salad extracts increase Salmonella growth at refrigeration temperatures

Panel A: Typical pictures of the fluid that accumulates in bagged salads.

Panel B and C: Histograms showing growth of an inoculum of $10^{1} \mathrm{CFU} / \mathrm{ml}$ Salmonella in sterile water supplemented with 5-20\% (v/v) doses of filtersterilised fluids taken from a bagged spinach (panel B) or bagged mixed leaf salad (panel C). Cultures (in triplicate) were incubated statically at $4{ }^{\circ} \mathrm{C}$, and samples withdrawn at daily intervals and enumerated for viable bacteria by serial dilution onto Luria agar and subsequent counting of colonies; $\mathrm{n}=3$. Key: ${ }^{\star}(\mathrm{p} \leq 0.05),{ }^{* *}(\mathrm{p} \leq 0.01),{ }^{* *}(\mathrm{p} \leq 0.001),{ }^{* * *}(\mathrm{p} \leq 0.0001)$. Note: the data shown was reproduced with permission from Koukkidis et al (2016) [27]. 
It is noteworthy that the salad bag water would have contained sanitising agents, even though it was stimulatory to growth. Of concern was the finding that salad juice including that leaching into salad bag water enhanced Salmonella biofilm formation and salad leaf colonization (Figure 2A). Scanning electron microscopy analysis of Salmonella interaction with spinach leaves showed a marked preference for stomata association, which is similar to that found by other studies [10,28]. Interestingly, the endogenous salad microflora were not as responsive to the salad leaf juice as the Salmonella (Figure 2B), suggesting that Salmonella gains an advantage over the salad microbes from fluids released from leaf damage. We also found that salad leaf juice treatment increased pathogen motility, which is important in biofilm formation as well as attachment of the Salmonella to abiotic surfaces such as a salad bag plastic container (Figure 3A, 3B and 3C). Collectively, this data suggests the salad bag itself could be an unappreciated vehicle by which pathogens are retained within bagged fresh salad leaves.

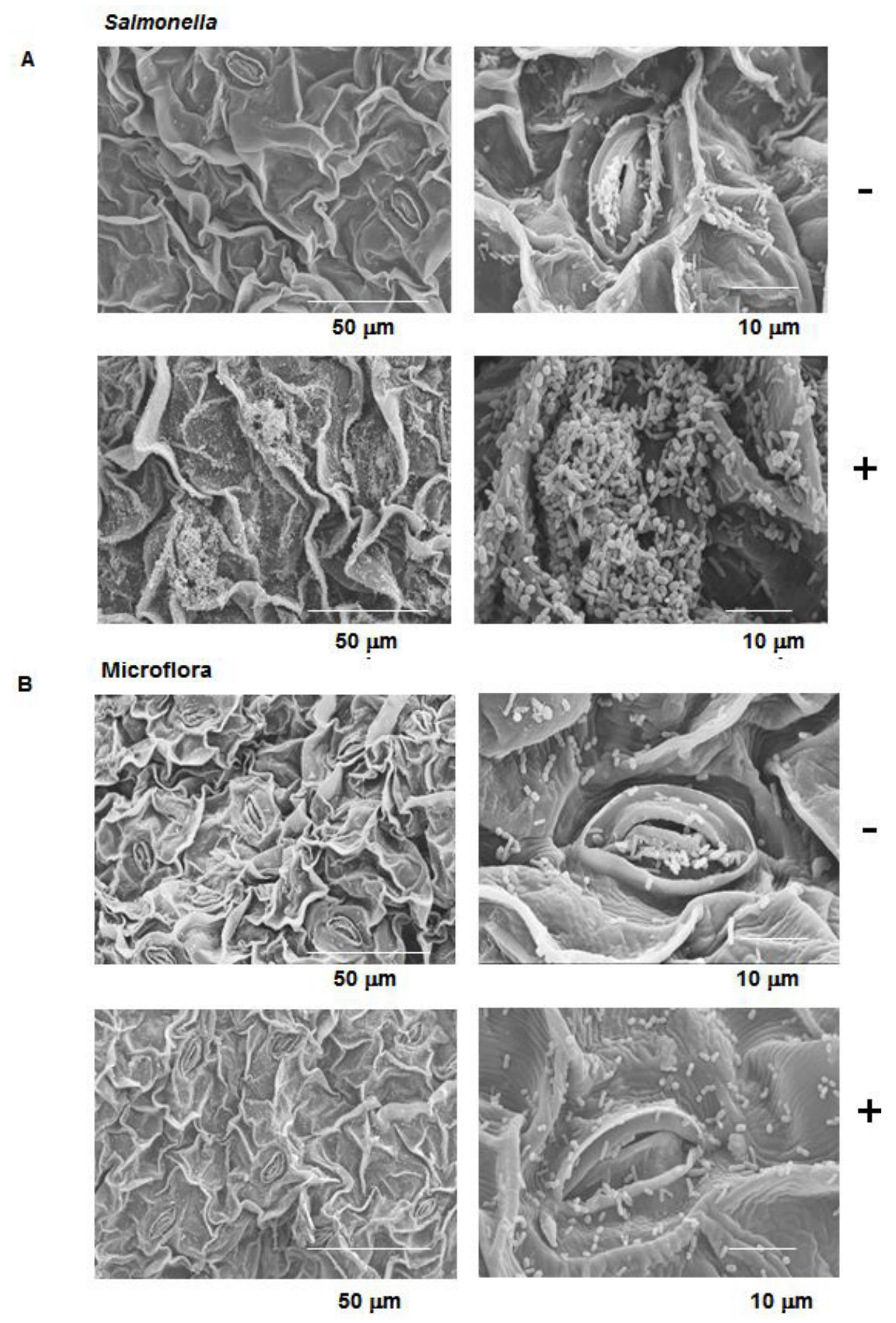

Figure 2: Spinach leaf extracts increase Salmonella colonisation of salad leaves

Panel A: Images showing representative scanning electron micrographs of the attachment to salad leaves of untreated (-) and filtersterilised spinach $\left(2 \%(\mathrm{v} / \mathrm{v})\right.$ juice-exposed $(+)$ Salmonella seeded at $10^{5} \mathrm{CFU} / \mathrm{ml}$ onto $5 \mathrm{~mm}$ sections of spinach leaves in sterile water which were then incubated statically at room temperature for 24 hours.

Panel B: Attachment profiles of the spinach leaf microflora in the absence $(-)$ and presence $(+)$ of $2 \%(v / v)$ spinach juice; $n=3$. Scale bars are shown on the bottom of each set of images. Note: the data shown was reproduced with permission from Koukkidis et al. (2016) [27]. 
A

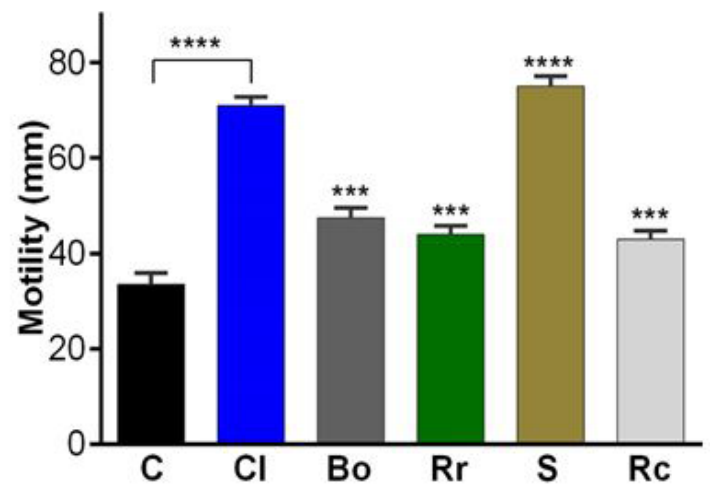

$\mathbf{B}$
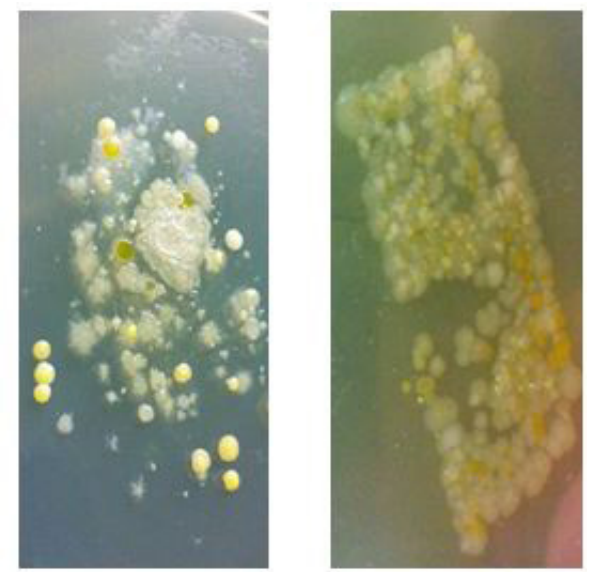

C

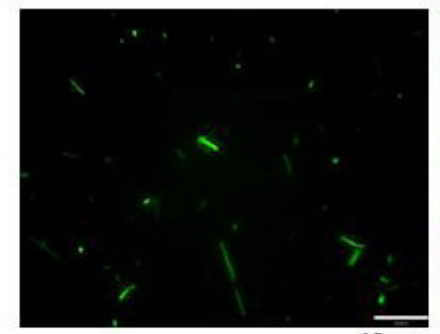

Control

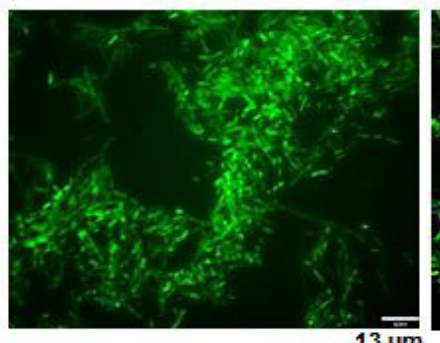

Spinach juice

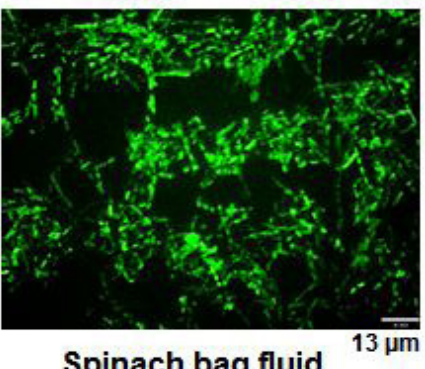

Spinach bag fluid

Figure 3: Salad leaf juices enhance Salmonella motility and salad bag colonisation

Panel A: Histograms showing that $2 \%(\mathrm{v} / \mathrm{v})$ additions of filter-sterilised salad extracts increase Salmonella motility in DMEM medium solidified with $0.3 \% \mathrm{w} / \mathrm{v}$ agar relative to controls ( $\mathrm{p} \leq 0.01$ ). Key: C, control (no additions); $\mathrm{Cl}$, cos lettuce; Bo, baby green oak lettuce; $\mathrm{Rr}$, red romaine lettuce; S, spinach; Rc, red chard; motility readings were taken after 24 hours incubation at $37{ }^{\circ} \mathrm{C} ; \mathrm{n}=5$. Panel B: Typical pictures of the diversity of microbes transferred from 4 by $1 \mathrm{~cm}$ sections of the interior surface of a salad bag pressed onto $9 \mathrm{~cm}$ plates of Luria agar; images shown are of microbial growth after 24 hours incubation at room temperature. Panel C: Blue light microscopy images (x40 magnification) of the biofilm formed by Green Fluorescent Protein-labelled Salmonella seeded at $10^{3} \mathrm{CFU} / \mathrm{ml}$ onto strips of salad bag plastic that had been incubated for 18 hours at room temperature in water in the absence $(-)$ and presence $(+)$ of $2 \%(\mathrm{v} / \mathrm{v})$ spinach juice; $\mathrm{n}=3$. Key: ${ }^{*}(\mathrm{p} \leq 0.05),{ }^{* *}(\mathrm{p} \leq 0.01),{ }^{* *}(\mathrm{p} \leq 0.001),{ }^{* * *}(\mathrm{p} \leq 0.0001)$. Note: data was reproduced with permission from Koukkidis et al (2016) [27].

\section{Reduction strategies}

\section{Produce Growers}

It has proved difficult to eliminate Salmonella (and indeed other enteric pathogens) from the fresh produce food chain and in the last 15 years in spite of considerable research efforts Salmonella infections associated with fresh food have not declined in the United States or the UK and the rest of Europe where they continue to cause the largest number of food-related hospital admissions [29-32]. In response to this serious health challenge a series of contamination source identification and reduction strategies have been applied in order to reduce Salmonella contamination of fresh salad produce at all levels of production, distribution, and retail. Research by Bartz et al. (2017) examined the origins of microbial contamination in an agricultural fresh produce production environment [33]. They looked at the source potential for enteropathogen fresh produce contamination of farm workers' hands, culture soil/compost and wash water. The study found that contamination was most likely to come from worker's hands rather than soil or water, and emphasised the importance of good hand hygiene. Other research suggests fresh produce washing methods and food compatible washing solutions are equally important in preventing salad leaf contamination [3]. The effectiveness of washing depends on the microbial content of the wash water if it is recycled, the type of sanitising agent, and the location of 
the colonized pathogen (surface or internalized). The aim of salad growers is an effective sanitizing treatment that eradicates colonized pathogens without affecting the taste or texture quality of the fresh produce. Decontamination protocols for salad leaves therefore generally involves treatment with a topical sanitizing agent, generally food compatible acids such as sodium hypochlorite, chlorinated water or oxidising agents such as hydrogen peroxide, or chlorine dioxide [3]. Klintham et al. (2017) evaluated the use of water microbubbles with and without oxidising sanitizers (acidic electrolyte water, chlorine dioxide, and sodium hypochlorite) on eradication of Salmonella from salad herbs [34]. Microbubbles alone did not possess any antimicrobial activity but did improve the efficacy of the chlorine dioxide, and sodium hypochlorite, which resulted in a 2-3 log reduction in Salmonella viability after only 5 minutes treatment [34]. Irradiation has also been used to control Salmonella and other enteric pathogen numbers, though such treatments can negatively affect salad leaf sensory characteristics [3]. However, the effectiveness of washing with surface acting sanitizers is much reduced if the Salmonella have already internalized into the salad leaves [3]. Chen et al. (2018) showed that the combination of lactic acid bacteria along with UV-C irradiation could reduce Salmonella enterica serovar Enteritidis levels by 2 logs in comparison with a simple distilled water treatment wash [35]. Thung et al. (2017) showed that a bacteriophage specific for Salmonella Enteritidis reduced significantly Salmonella numbers by 2 logs in a variety of fresh produce products after incubation at $4^{\circ} \mathrm{C}$ for 48 hours [36]. The bacteriophage was stable in a broad spectrum of temperature and $\mathrm{pH}$ conditions and so could be applicable for fresh cut salads [36]. Research by Jiang et al. (2017) showed that cold plasma activated peroxide aerosol droplet treatment reduced Salmonella numbers on Spinach leaves by 4.2 logs [37]. This treatment also reduced significantly naturally present spoilage microorganisms, without affecting the quality of the salad leaves [38]. In another study, Shen et al. (2017) attempted to limit the internalisation of S. enterica into mung bean sprouts by applying 12 different endophytic Bacillus subtilis strains. The results found within 5 days that 3 of the Bacillus strains were able to reduce Salmonella internalization by up to $1.4 \mathrm{log}$ CFU/g of seed sprouts [39]. Several other studies have also looked at the salad leaf endogenous microflora as a means of improving the microbiological safety of salad leaves by competitive exclusion [40]. Lactic acid bacteria (which produce growth repressing bacteriocins) inhibited over $2 \log$-fold the growth of $S$. enterica serovar Typhimurium inoculated onto fresh-cut lettuce, while the combination of pathogen specific bacteriophages with antagonistic bacteria such as Enterobacter reduced the in vitro growth of Salmonella by 6 log orders.

The results of Koukkidis et al. (2016) highlighted for salad leaf growers the importance of minimising salad leaf damage during handling, maintaining good hygiene during production, harvest and post-harvest handling to reduce the risk of pathogen contamination $[3,27,41]$. This study suggests more frequent checks are needed of the growing medium where salad vegetables are cultured for the significant presence of enteric pathogens [27]. Also, the water used for fresh produce washing should be free of any pathogens especially if recycled as build-up of fluids from the cut ends of salad leaves has the potential to increase numbers of pathogens present within the leaves. Within salad leaf packaging it would limit pathogen growth if the fresh produce was without an excess of water, as salad bag fluid containing cut leaf exudate is clearly able enhance Salmonella growth and virulence, even at refrigeration temperatures.

\section{Distributors}

Despite the efforts to prevent fresh produce contamination there are as yet no food-safe treatments which can remove foodborne pathogens from fresh salad leaves without causing major leaf damage. The adoption of a holistic approach to the microbiological safety of fresh produce is key, and for distributors this would be to consistently maintain low temperatures after harvesting, and to avoid where possible damage to the salad leaves [3]. Within salad leaf packaging it would help limit pathogen growth if the salad leaves were packed without an excess of water, as leaf exudate from cut lettuce and spinach leaves is clearly able enhance Salmonella growth and virulence, even at refrigeration temperatures and irrespective of whether sanitizing agents were originally present [27]. Reducing the use by date of bagged salads would minimise the opportunity of any pathogens that might have entered the salad to increase in numbers during refrigerated storage. Currently it may be as long as 6-7 days from leaf harvest to customer consumption [3].

\section{Consumers}

As it has been shown pathogens can grow within bagged salads, it is advisable to always buy fresh salad leaves as far as possible from their use by date [27]. Do not buy bags with damaged leaves or which appear swollen like a balloon even if within their use by date. Buy smaller bags which can be consumed within one sitting if possible, or use within one day of opening. Refrigerate the salad promptly after purchase as bacteria tend to grow faster at room temperature. When ready to serve the salad leaves remove all leached juices from the salad bag with a thorough wash (at least 30 seconds under the cold tap). Washing a freshly opened bag of salad is important even if the product is labelled as 'washed and ready to eat', as it would help to ensure the removal of any contaminated soil or loosely attached bacteria that are resident on the surface of the leaves [27]. If planning to eat the salad later, re-seal the bag eliminating as much air as possible which would help limit growth of any pathogens present by denying them access to atmospheric oxygen. Ideally, repeat this procedure with salad transferred to a fresh plastic bag as pathogenic bacteria such as Salmonella are able to attach and grow on the plastic inner surface of salad containers [27]. Hands should also be washed thoroughly before and after handling the salad leaves $[42,43]$. 


\section{Conclusion}

Food safety is a major issue within the agricultural fresh food chain. Meat products have long been recognised as a source of potential food poisoning, and now it is clear that because they are minimally processed after harvesting and usually eaten raw salad leaves have a recognised food infection risk $[3,4,7,8,10]$. Much effort has therefore been invested in devising ways to prevent fresh salad contamination such as testing for and reducing pathogen levels at source as well as improving protocols for post-harvest processing and packaging, but these have had variable success and outbreaks still occur [3,44,45]. A strong holistic and integrated approach involving growers and distributors is therefore needed to develop well monitored agricultural systems that will ensure the production and delivery of safe salad vegetables. For the salad leaf consumer, improvements in food safety awareness similar to that associated with meat and dairy products is needed, and it is reassuring that governmental bodies such as the UK NHS and Food Standards Agency are now providing guidance on washing and storage of fresh salad produce.

\section{Competing Interests and Disclosures}

Neither of the authors have any conflict of interest in publication of this paper, nor any financial or other issues to disclose.

\section{Acknowledgement}

GK gratefully acknowledges the support of the BBSRC (BB/L016958/1) in the form of an industrial-CASE studentship.

\section{References}

1. Rekhy R, McConchie R ?(2014) Promoting consumption of fruit and vegetables for better health. Have campaigns delivered on the goals?. Appetite. 79: 113-23.

2. Wang X, Ouyang Y, Liu J, Zhu M, Zhao G, et al. (2014) Fruit and vegetable consumption and mortality from all causes, cardiovascular disease, and cancer: systematic review and dose-response meta-analysis of prospective cohort studies. BMJ 349: g4490

3. Olaimat AN, Holley RA (2012) Factors influencing the microbial safety of fresh produce: A review. Food Microbiol 32: 1-19

4. Crowe SJ, Mahon BE, Vieira AR, Gould LH (2015) Vital Signs: Multistate Foodborne Outbreaks - United States, 2010-2014. Morbidity Mortality Weekly Report 64: 1221-5.

5. Callejon RM, Rodriguez-Naranjo MI, Ubeda C, Hornedo-Ortega R, Garcia-Parrilla MC, et al. (2015) Reported Foodborne Outbreaks Due to Fresh Produce in the United States and European Union: Trends and Causes. Foodborne Pathog Dis 12: 32-8.

6. Taban BM, Halkman AK (2011) Do leafy green vegetables and their ready-to-eat [RTE] salads carry a risk of foodborne pathogens? Anaerobe 17: 286-7.

7. Klerks MM, Franz E, van Gent-Pelzer M, Zijlstra C, van Bruggen AHC (2007) Differential interaction of Salmonella enterica serovars with lettuce cultivars and plant-microbe factors influencing the colonization efficiency. Isme J 1: 620-31.

8. Abadias M, Usall J, Anguera M, Solson C, Vinas I (2008) Microbiological quality of fresh, minimally-processed fruit and vegetables, and sprouts from retail establishments. Int J Food Microbiol 123: 121-9.

9. Schikora A, Garcia AV, Hirt H (2012) Plants as alternative hosts for Salmonella. Trends Plant Sci 17: 245-9.

10. Berger CN, Sodha SV, Shaw RK, Griffin PM, Pink D, et al. (2010) Fresh fruit and vegetables as vehicles for the transmission of human pathogens. Environ Microbiol 12: 2385-97.

11. FDA. FDA Investigated Multistate Outbreak of Salmonella Infections Linked to Alfalfa Sprouts.

12. Nygard K, Lassen J, Vold L, Andersson Y, Fisher I, et al. (2008) Outbreak of Salmonella Thompson infections linked to imported rucola lettuce. Foodborne Pathog Dis 5: 165-73.

13. Pakalniskiene J, Falkenhorst G, Lisby M, Madsen SB, Olsen KE, et al. (2009) A foodborne outbreak of enterotoxigenic E. coli and Salmonella Anatum infection after a high-school dinner in Denmark, November 2006. Epidemiol Infect 137: 396-401.

14. Beech A. Lettuce linked to salmonella outbreak may have been exported overseas.

15. Blucher A, ABC News. Salmonella outbreak: Tasmanian salad leaf grower takes financial hit despite safe product.

16. EFSA (2013) EFSA Panel on Biological Hazards (BIOHAZ) Panel; Scientific Opinion on the risk posed by pathogens in food of non-animal origin. Part 1 (outbreak data analysis and risk ranking of food/pathogen combinations). EFSA Journal 1-138.

17. World Health Organization. Salmonella (non-typhoidal), Fact Sheet.

18. Olaimat AN, Holley RA (2012) Factors influencing the microbial safety of fresh produce: A review. Food Microbiol 32: 1-19.

19. Centers for Disease Control and Prevention, U.S. Department of Health \& Human Services. Pathogens causing US foodborne illnesses, hospitalizations, and deaths, 2000-2008.

20. European Food Safety Authority, European Centre for Disease Prevention and Control (2016) The European Union summary report on trends and sources of zoonoses, zoonotic agents and food-borne outbreaks in 2016. EFSA Journal 14: e04634.

21. Warriner K, Huber A, Namvar A, Fan W, Dunfield K (2009) Recent advances in the microbial safety of fresh fruits and vegetables. Adv Food Nutr Res 57: $155-208$

22. Brandl MT (2006) Fitness of human enteric pathogens on plants and implications for food safety. Annu Rev Phytopathol 44: 367-92.

23. Guo X, Chen J, Brackett R, Beuchat L (2001) Survival of Salmonellae on and in tomato plants from the time of inoculation at flowering and early stages of fruit development through fruit ripening. Appl Environ Microbiol 67: 4760-4.

24. Guo X, van Iersel M, Chen J, Brackett R, Beuchat L (2002) Evidence of association of salmonellae with tomato plants grown hydroponically in inoculated nutrient solution. Appl Environ Microbiol 68: 3639-43.

25. Schikora A, Carreri A, Charpentier E, Hirt H (2008) The Dark Side of the Salad: Salmonella typhimurium Overcomes the Innate Immune Response of Arabidopsis thaliana and Shows an Endopathogenic Lifestyle. Plos One 3: e2279. 
26. Deering AJ, Pruitt RE, Mauer LJ, Reuhs BL (2012) Examination of the internalization of Salmonella serovar Typhimurium in peanut, Arachis hypogaea, using immunocytochemical techniques. Food Res Int. 45: 1037-43.

27. Koukkidis G, Haigh R, Allcock N, Jordan S, Freestone P (2017) Salad Leaf Juices Enhance Salmonella Growth, Colonization of Fresh Produce, and Virulence. Appl Environ Microbiol. 83: e02416-16.

28. Kroupitski Y, Golberg D, Belausov E, Riky Pinto, David Granot, et al. (2009) Internalization of Salmonella enterica in Leaves Is Induced by Light and Involves Chemotaxis and Penetration through Open Stomata. Appl Environ Microbiol 75: 6076-86.

29. Centers for Disease Control and Prevention, U.S. Department of Health \& Human Services. Making Food Safer to Eat.

30. O'Brien SJ, Larose TL, Adak GK, Evans MR, Tam CC, (2016) Modelling study to estimate the health burden of foodborne diseases: cases, general practice consultations and hospitalisations in the UK, 2009. BMJ Open 6: e011119.

31. EFSA. Salmonella cases no longer falling in the EU.

32. EFSA (2017) The European Union summary report on trends and sources of zoonoses, zoonotic agents and food-borne outbreaks in 2016. EFSA Journal 15: e05077

33. Bartz FE, Lickness JS, Heredia N, Newman KL, Hodge DW, et al. (2017) Contamination of Fresh Produce by Microbial Indicators on Farms and in Packing Facilities: Elucidation of Environmental Routes. Appl Environ Microbiol 83: e02984-16.

34. Klintham P, Tongchitpakdee S, Chinsirikul W, Mahakarnchanakul W (2017) Combination of microbubbles with oxidizing sanitizers to eliminate Escherichia coli and Salmonella Typhimurium on Thai leafy vegetables. Food Control 77: 260-9.

35. Chen A, Luo W, Luo Y, Zhu B (2017) Combined treatment of ultraviolet-C and L. plantarum on Salmonella enteritidis and quality control of fresh-cut apple. J Food Process Preserv 42: e13349.

36. Thung TY, Krishanthi Jayarukshi Kumari Premarathne, Jayasekara Mudiyanselage, San Chang W, Ying Loo Y, et al. (2017) Use of a lytic bacteriophage to control Salmonella Enteritidis in retail food. LWT - Food Sci Technol 78: 222-5.

37. Jiang Y, Sokorai K, Pyrgiotakis G, Demokritou P, Li X, et al. (2017) Cold plasma-activated hydrogen peroxide aerosol inactivates Escherichia coli O157:H7, Salmonella Typhimurium, and Listeria innocua and maintains quality of grape tomato, spinach and cantaloupe. Int J Food Microbiol 249: 53-60.

38. Thorn RMS, Pendred J, Reynolds DM (2017) Assessing the antimicrobial potential of aerosolised electrochemically activated solutions (ECAS) for reducing the microbial bio-burden on fresh food produce held under cooled or cold storage conditions. Food Microbiol 68: 41-50.

39. Shen Z, Mustapha A, Lin M, Zheng G (2017) Biocontrol of the internalization of Salmonella enterica and Enterohaemorrhagic Escherichia coli in mung bean sprouts with an endophytic Bacillus subtilis. Int J Food Microbiol 250: 37-44.

40. Gorni C, Allemand D, Rossi D, Mariani P (2015) Microbiome profiling in fresh-cut products. Trends Food Sci Technol 46: $295-301$.

41. Ye J, Kostrzynska M, Dunfield K, Warrineri K (2010) Control of Salmonella on Sprouting Mung Bean and Alfalfa Seeds by Using a Biocontrol Preparation Based on Antagonistic Bacteria and Lytic Bacteriophages. J Food Prot 73: 9-17.

42. Public Health of England. E. coli O157 national outbreak update.

43. National Health System, United Kingdom. How to wash fruit and vegetables.

44. FDA. Guide to minimize microbial food safety hazards for fresh fruits and vegetables.

45. WHO. Microbiological hazards in fresh fruits and vegetables.

46. Centers for Disease Control and Prevention, U.S. Department of Health \& Human Services. Multistate Outbreak of Salmonella Montevideo Infections Linked to Raw Sprouts.

47. Centers for Disease Control and Prevention, U.S. Department of Health \& Human Services. Multistate Outbreak of Salmonella Infections Linked to Alfalfa Sprouts from One Contaminated Seed Lot.

48. Centers for Disease Control and Prevention, U.S. Department of Health \& Human Services. Multistate Outbreak of Salmonella Reading and Salmonella Abony Infections Linked to Alfalfa Sprouts.

49. The Guardian-Australian Associated Press. Number of salmonella cases in Victoria linked to lettuce doubles to reach 54.

50. Centers for Disease Control and Prevention, U.S. Department of Health \& Human Services. Multistate Outbreak of Salmonella Poona Infections Linked to Imported Cucumbers.

51. Centers for Disease Control and Prevention, U.S. Department of Health \& Human Services. Multistate Outbreak of Salmonella Enteritidis Infections Linked to Bean Sprouts.

52. Centers for Disease Control and Prevention, U.S. Department of Health \& Human Services. Outbreak of Salmonella Newport Infections Linked to Cucumbers. 53. Centers for Disease Control and Prevention, U.S. Department of Health \& Human Services. Multistate Outbreak of Human Salmonella Enteritidis Infections Linked to Alfalfa Sprouts and Spicy Sprouts.

54. Centers for Disease Control and Prevention, U.S. Department of Health \& Human Services. Multistate Outbreak of Human Salmonella I 4,[5],12:i:- Infections Linked to Alfalfa Sprouts.

55. Centers for Disease Control and Prevention, U.S. Department of Health \& Human Services. Multistate Outbreak of Human Salmonella Newport Infections Linked to Raw Alfalfa Sprouts.

56. Centers for Disease Control and Prevention, U.S. Department of Health \& Human Services. Multistate Outbreak of Salmonella Saintpaul Infections Linked to Raw Alfalfa Sprouts.

57. Rimhanen-Finne R, Niskanen T, Lienemann T, Johansson T, Sjöman M, et al.(2011) A Nationwide Outbreak of Salmonella Bovismorbificans Associated with Sprouted Alfalfa Seeds in Finland, 2009. Zoonoses and Public Health 58: 589-96.

58. Werner S, Boman K, Einemo I, Erntell M, de Jong B, et al. (2007) Outbreak of Salmonella Stanley in Sweden associated with alfalfa sprouts, July-August 2007. Euro Surveill 12: E071018.2.

59. Emberland KE, Ethelberg S, Kuusi M, Vold L, Jensvoll L, et al. (2007) Outbreak of Salmonella Weltevreden infections in Norway, Denmark and Finland associated with alfalfa sprouts, July-October 2007. Euro Surveill 12: E071129.4. 


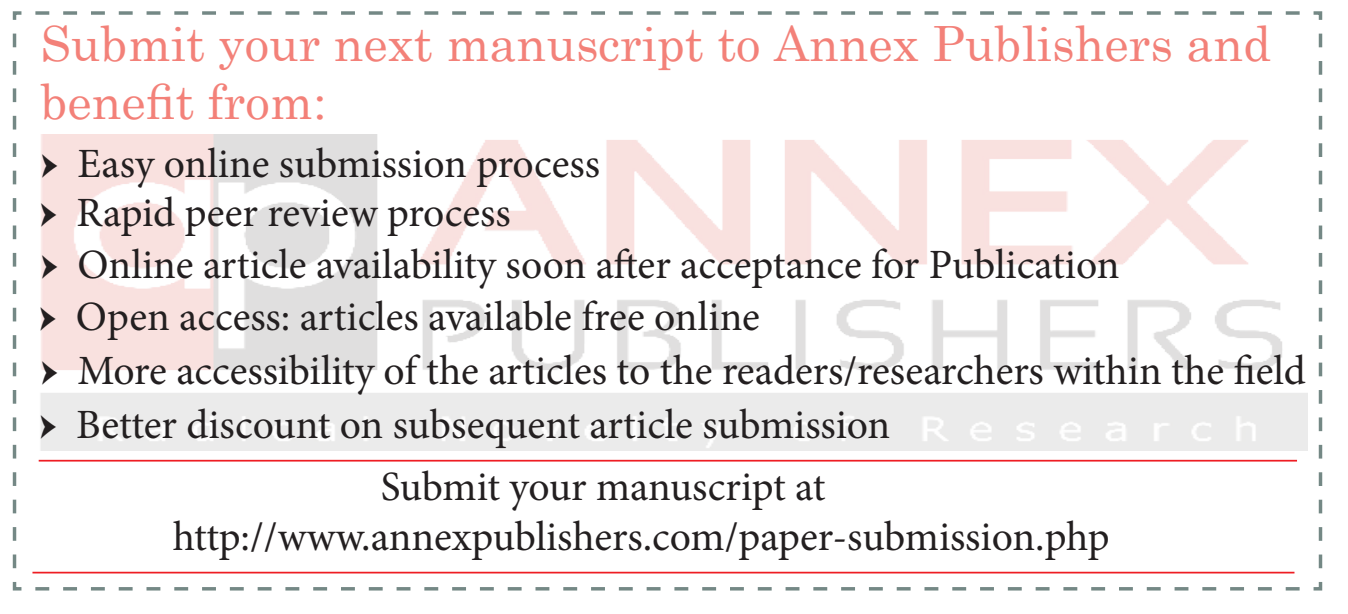

